\title{
Variable Gain PI Controller Design For Speed Control of a Doubly Fed Induction Motor
}

\author{
Using State-Space Nonlinear Approach
}

\author{
T. Mohammed Chikouche \\ Dpt of Electrotechnics, \\ University of Saida, \\ Algeria \\ tarekchi@yahoo.fr
}

\author{
A. Mezouar \\ Dpt of Electrotechnics, \\ University of Saida, \\ Algeria \\ a.mezouar@yahho.fr
}

\author{
T. Terras \\ Dpt of Electrotechnics, \\ University of Saida, \\ Algeria \\ t_tahar2000@yahoo.fr
}

\author{
S. Hadjeri \\ Dpt of Electrotechnics \\ Djillali Liabes University of \\ Sidi Bel Abbes, Algeria \\ shadjeri2@yahoo.fr
}

\begin{abstract}
This paper presents a comparison between a variable gain PI controller and a conventional PI controller used for speed control with an indirect field orientation control of a Doubly Fed Induction Motor (DFIM), fed by two PWM inverters with a separate DC bus link. By introducing a new approach for decoupling the motor's currents in a rotating (d-q) frame, based on the state space input-output decoupling method, we obtain the same transfer function (1/s) for all four decoupled currents. Thereafter, and in order to improve control performance, the VGPI controller was used for speed regulation. The results obtained in Matlab/Simulink environment illustrate the effectiveness of the technique employed for the decoupling and for speed regulation.
\end{abstract}

Keywords: doubly fed induction motor (DFIM); input output decoupling; field-oriented control; variable gain PI controller; conventional PI controller.

\section{APPENDIX}

DFIM Doubly Fed Induction Motor.

VGPI Variable Gain PI.

$s, r \quad$ Stator and Rotor indices,

$d, q \quad$ Indices of the orthogonal components direct and quadrature.

$\bar{X} \quad$ Complex variable such as: $X=\operatorname{Re}[\bar{X}]+j \operatorname{Im}[\bar{X}]$.

$R_{s}, R_{r}$ Stator and Rotor resistances.

$L_{s}, L_{r} \quad$ Stator and Rotor inductances.

$T_{s}, T_{r} \quad$ Stator and rotor time constant.

$\sigma \quad$ Leakage factor $\left(\sigma=1-M_{s r}^{2} / L_{s} L_{r}\right)$.

$M_{s r} \quad$ Mutual inductance.

$\theta \quad$ The electrical rotor position.

$\theta_{s}, \theta_{r}$ Statoric flux position, Rotoric flux position.

$\omega \quad$ The mechanical rotor frequency.

$\Omega \quad$ Mechanical speed.

$\omega_{s} \quad$ Electrical stator frequency.

$P \quad$ Number of pole pairs.

$T_{e m} \quad$ Electromagnetic torque.
$T_{r} \quad$ Load torque.

$J \quad$ Moment of inertia.

$f \quad$ Friction coefficient.

Rated data of the simulated doubly fed induction motor: Rated values: $1.5 \mathrm{KW}$; 220/380V-50Hz;

Rated parameters:

$$
\begin{aligned}
& R_{s}=1.75 \Omega \\
& R_{r}=1.68 \Omega \\
& L_{s}=0.295 \mathrm{H} \\
& L_{r}=0.104 \mathrm{H} \\
& M=0.165 \mathrm{H} \\
& P=2.0
\end{aligned}
$$

Mechanical constants

$$
\begin{aligned}
& J=0.01 \mathrm{Kg} . \mathrm{m}^{2} \\
& f=0.00 I . S .
\end{aligned}
$$

\section{INTRODUCTION}

The progress accomplished, in the few past years, in power electronics has made the Doubly Fed Induction Motor (DFIM) an industrial standard due to its low cost and high reliability [1, 2]. The DFIM is an electrical three-phase asynchronous machine with wound rotor accessible for control. Since the power handled by the rotor side (slip power) is proportional to the slip, the energy requires a rotor-side power converter which handles only a small fraction of the overall system power [3, 4]. It is very attractive for both energy generation and high power drive applications.

In recent years, there has been a great amount of activity on back stepping control approach in AC drive fields [3].The non linear control approach shows better precision and stability. However, its major problem is its sensitivity to motor parameter variations and load disturbance.

DFIM control issues are traditionally handled by fixed gain proportional integral (PI) controllers. However, the fixed gain controllers are very sensitive to parameter variations and cannot provide good dynamic performance. So, the controller 
parameters have to be continually adapted [5]. The VGPI controller gives better results in case of parameter variations for nonlinear systems. So, the DFIM is an ideal candidate to test its performance $[6,7]$.

The present work is about field-oriented control with VGPI controller of a DFIM employing the state space decoupling method.The vector control of the DFIM with two independent converters has been studied in several works recently. The linearization of the nonlinear model of the machine can be done in different manners with various terms of compensation $[5,6]$. In this paper, a nonlinear state space is proposed to ensure the decoupling of the multi-variables system input-ouput that constitutes the DFIM.

The paper is organized as follows: in section II the DFIM model is illustrated. Section III contains the field-oriented control of a DFIM based on the sate space decoupling method. Section IV is focused on the control speed of the DFIM using the VGPI controller. In Section V, simulations of the control system performed by MATLAB are presented and discussed.

\section{DFIM DYNAMIC MODEL}

The dynamic model of the DFIM in a $(d-q)$ synchronous rotating frame is given by the following voltages equations:

$\left\{\begin{array}{l}\bar{V}_{s}=R_{s} \bar{I}_{s}+\frac{d \bar{\phi}_{s}}{d t}+j \omega_{s} \bar{\phi}_{s} \\ \bar{V}_{r}=R_{r} \bar{I}_{r}+\frac{d \bar{\phi}_{r}}{d t}+j \omega_{r} \bar{\phi}_{r}\end{array}\right.$

Expressions of the fluxes are given by:

$\left\{\begin{array}{l}\bar{\phi}_{s}=L_{s} \bar{I}_{s}+M_{s r} \bar{I}_{r} \\ \bar{\phi}_{r}=L_{r} \bar{I}_{r}+M_{s r} \bar{I}_{s}\end{array}\right.$

From (1) and (2) the all currents state model is written as follows:

$\left\{\begin{array}{l}\frac{d \bar{I}_{s}}{d t}=-\frac{R_{s}}{\sigma L_{s}} \bar{I}_{s}+\frac{M_{s r} R_{r}}{\sigma L_{s} L_{r}} \bar{I}_{r}+\frac{1}{\sigma L_{s}} \bar{V}_{s}-\frac{M_{s r} R_{r}}{\sigma L_{s} L_{r}} \bar{V}_{r} \\ \frac{d \bar{I} r}{d t}=-\frac{R_{r}}{\sigma L_{r}} \bar{I}_{r}+\frac{M_{s r} R_{s}}{\sigma L_{s} L_{r}} \bar{I}_{s}+\frac{1}{\sigma L_{r}} \bar{V}_{r}-\frac{M_{s r} R_{r}}{\sigma L_{s} L_{r}} \bar{V}_{s}\end{array}\right.$

The mechanical equation is expressed by (4):

$\frac{J}{p} \frac{d \omega}{d t}=T_{e m}-\frac{f \omega}{p}-T_{r}$

With: $\omega=p . \Omega$

And the electromagnetic torque is given by:

$T_{e m}=p M_{s r} I_{m}\left(\bar{I}_{s} \bar{I}_{r}^{*}\right)$

So, the equation for the speed variation becomes:
$\frac{J}{p} \frac{d \omega}{d t}=p M_{s r} I_{m}\left(\bar{I}_{s} \bar{I}_{r}^{*}\right)-\frac{f \omega}{p}-T$

\section{VECTOR CONTROL STRATEGY OF DFIM BY STATE SPACE DECOUPLING}

\section{A. Rotor Flux Oriented}

The principle for this type of control consists in orienting the flux into the machine, to the rotor, to the stator or in the air gap. Conventionally, we work with an orienting on the $d$ axis. The in quadrature axis will therefore carry the current that will participate in the creation of the electromagnetic torque in the machine [6, 8-9]

$\phi_{r q}=0 ; \phi_{r}=\phi_{r d}$

Then:

$I_{r q}=-\frac{M_{s r}}{L_{r}} I_{s q}$

The magnetization of the machine allows to impose the rotor flux module, so we distinguish two strategies $[6,10]$ :

- Working with a unitary power factor to stator or to rotor, which implies that one of the two currents $I_{s d}$ or $I_{r d}$ will be null, with: $\phi_{r d}=M_{s r} I_{s d}$

- Split the magnetizing current equally between the two converters, that is :

$$
\begin{aligned}
& I_{s d}=I_{r d}=\frac{I_{d}}{2}, \text { with: } \\
& \phi_{r d}=\left(L_{r}+M_{s r}\right) \frac{I_{d}}{2}
\end{aligned}
$$

The choice of $I_{r d}=0$, gives the same expression for the flux to the stator and to the air gap. In addition, the expression depends only on $M_{s r}$, and with a unitary power factor at the rotor.

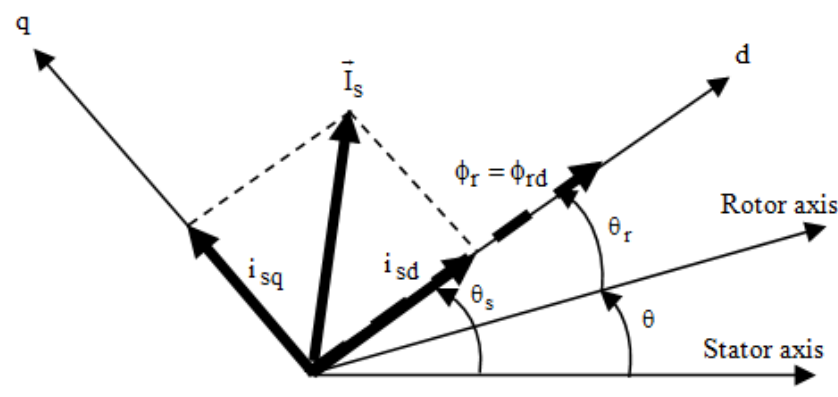

Fig. 1. Rotor flux oriented on the d axis 
B. Currents Decoupling - State Space

\section{B.1. Principle of the method:}

Consider the following multivariable system:

$$
\left\{\begin{array} { l } 
{ \dot { x } = A x + B u } \\
{ y = C x }
\end{array} \text { with } \left\{\begin{array}{lll}
x \in \mathfrak{R}^{n} & x=\left[\begin{array}{lll}
x_{1} & x_{2} \ldots & x_{n}
\end{array}\right]^{T} \\
y \in \mathfrak{R}^{m} & u=\left[\begin{array}{lll}
u_{1} & u_{2} \ldots & u_{m}
\end{array}\right]^{T} \\
u \in \mathfrak{R}^{m} & y=\left[\begin{array}{lll}
y_{1} & y_{2} \ldots & y_{m}
\end{array}\right]^{T}
\end{array}\right.\right.
$$

The objective is to determine a state space of the form:

$$
u=-K_{d} x+L v, \text { with } v \in \mathfrak{R}^{m}
$$

$v$ denotes the new input vector, which decouples the system, in a way that the output $y_{i}(\mathrm{i}=1$ to $\mathrm{m})$ depends only on the input $v$. The output $y_{i}$ is written:

$$
Y_{i}=C_{i} x
$$

Where $C_{i}$ is the i-th row of the matrix $C$. Let us derive $y_{i}$ a few times in order to bring up the command. We call characteristic index noted $\delta_{i}$, the number of derivation it takes in order to bring up the command.

We then have successively for each output $\mathrm{i}$ :

$$
\left\{\begin{array}{l}
\dot{y}_{i}=C_{i} \dot{x}=C_{i}(A x+B u)=C_{i} A x \text { with }: C_{i} B u=0 \\
\ddot{y}_{i}=C_{i} A \dot{x}=C_{i} A(A x+B u)=C_{i} A^{2} x \text { with }: C_{i} A B u=0 \\
\ddot{y}_{i}^{(3)}=C_{i} A^{2} \dot{x}=C_{i} A^{2}(A x+B u)=C_{i} A^{3} x \text { with }: C_{i} A^{2} B u=0 \\
\vdots \\
y_{i}^{\left(\delta_{i}\right)}=C_{i} A^{\delta_{i}} x+C_{i} A^{\chi_{i}-1} B u \text { with }:\left(C_{i} A^{\delta_{i}} B u \neq 0\right)
\end{array}\right.
$$

That we can still write in matrix form:

$$
\left[\begin{array}{c}
y_{1}^{\left(\delta_{1}\right)} \\
y_{2}^{\left(\delta_{2}\right)} \\
\vdots \\
y_{2}^{\left(\delta_{m}\right)}
\end{array}\right]=\left[\begin{array}{c}
C_{1} A^{\delta_{1}} \\
C_{2} A^{\delta_{2}} \\
\vdots \\
C_{m} A^{\delta_{m}}
\end{array}\right] x+\left[\begin{array}{c}
C_{1} A^{\delta_{1}-1} B \\
C_{2} A^{\delta_{2}-1} B \\
\vdots \\
C_{m} A^{\delta_{m}-1} B
\end{array}\right] u
$$

that is:

$$
y^{*}=A^{*} x+B^{*} u
$$

With $y^{*} \in \mathfrak{R}^{m}, A^{*} \in \mathfrak{R}^{m \times m}$ and $B^{*} \in \mathfrak{R}^{m \times m}$. We seek a control law $u=-K_{d} x+L_{d} v$ such as $y^{*}=v$. The looped system is written as:

$$
y^{*}=A^{*} x+B^{*}\left(-K_{d} x+L_{d} v\right)=\left(A^{*}-B^{*} K_{d}\right) x+B^{*} L_{d} v
$$

To obtain $y^{*}=v$ we must have $B^{*} L_{d}=1$ and $A^{*}-B^{*} K_{d}=0$. If the matrix $\mathrm{B}^{*}$ is invertible, the choice of :

$$
K_{d}=\left(B^{*}\right)^{-1} A^{*} \text { and } L=\left(B^{*}\right)^{-1}
$$

gives:

$$
y^{*}=v
$$

that is:

$$
Y_{i}(s)=\frac{1}{s^{\delta_{i}+1}} V_{i}(s)
$$

\section{B.2 Application to the DFIM:}

We search to exploit this method for decoupling the currents of the machine projected on a (d-q) rotating frame [6, $11,12]$. Starting from (3) and choosing a state vector equal to the output vector, formed of four currents of the machine. The input vector is formed of supply voltages. Then we obtain the following expression:

$$
\begin{aligned}
& \dot{x}=A x+B u \\
& y=C x
\end{aligned}
$$

With: $x=\left[\begin{array}{llll}I_{s d} & I_{s q} & I_{r d} & I_{r q}\end{array}\right]^{T}$ the state vector (for all currants) and $u=\left[\begin{array}{llll}V_{s d} & V_{s q} & V_{r d} & V_{r q}\end{array}\right]^{T}$ the input vector voltages.

$A=\left[\begin{array}{cccc}-a_{2} & a_{1} \omega+\omega_{s} & a_{3} & a_{5} \omega \\ -a \omega-\omega_{s} & -a_{1} & -a_{5} \omega & a_{3} \\ a_{4} & -a_{6} \omega & -a_{2} & -\frac{\omega}{\sigma}+\omega_{s} \\ a_{6} \omega & a_{4} & \frac{\omega}{\sigma}-\omega_{s} & -a_{2}\end{array}\right]$

$B=\left[\begin{array}{cccc}b_{1} & 0 & -b_{3} & 0 \\ 0 & b_{1} & 0 & -b_{3} \\ -b_{3} & 0 & b_{2} & 0 \\ 0 & -b_{3} & 0 & b_{2}\end{array}\right] C=\left[\begin{array}{cccc}1 & 0 & 0 & 0 \\ 0 & 1 & 0 & 0 \\ 0 & 0 & 1 & 0 \\ 0 & 0 & 0 & 1\end{array}\right]$

where: $\quad a=\frac{1-\sigma}{\sigma} \quad ; \quad a_{1}=\frac{R_{s}}{\sigma L_{s}} \quad ; \quad a_{2}=\frac{R_{r}}{\sigma L_{r}}$ $a_{3}=\frac{R_{r} M_{s r}}{\sigma L_{s} L_{r}} ; a_{4}=\frac{R_{s} M_{s r}}{\sigma L_{s} L_{r}} ; \quad a_{5}=\frac{M_{s r}}{\sigma L_{s}} ; a_{6}=\frac{M_{s r}}{\sigma L_{r}} ;$

$b_{1}=\frac{1}{\sigma L_{s}} ; b_{2}=\frac{1}{\sigma L_{r}} b_{3}=\frac{M_{s r}}{\sigma L_{s} L_{r}} ; \sigma=1-\frac{M_{s r}^{2}}{\sigma L_{s} L_{r}}$ 
The choice of $x=y$ makes the system completely controllable and observable. In applying the decoupling method on this system, it follows that:

$$
\forall i ; \delta_{i}=0 \text { and }\left\{\begin{array}{l}
L_{d}=B^{-1} \\
K_{d}=B^{-1} A
\end{array}\right.
$$

$y^{*}=v$, therefore:

$$
\frac{Y_{i}(s)}{V_{i}(s)}=\frac{1}{s}
$$

The four currents are decoupled and thus governed by the same transfer function in open loop: $G(s)=1 / s$.

\section{Design the Control Loops}

\section{C.1 Currents control}

The currents are decoupled and then we can consider a state space correction with the method of placement of poles. The principal schematic diagram of this correction is given by the Figure 2.

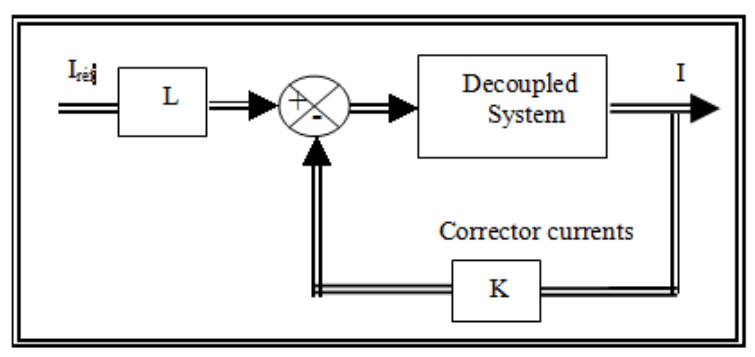

Fig. 2. Current regulation by state spaces

To ensure the same response for the current loop, the next choice can be adopted.

$$
L=K=\left[\begin{array}{cccc}
k & 0 & 0 & 0 \\
0 & k & 0 & 0 \\
0 & 0 & k & 0 \\
0 & 0 & 0 & k
\end{array}\right]
$$

So the transfer function of each current closed loop will be of the form:

$$
H(s)=\frac{k}{s+k}
$$

\section{C.2 Speed Control}

The mechanical equation is given by:
$J \frac{d \Omega}{d t}=T_{e m}-f \Omega-T_{r}$

The orientation of the rotor flux on the $\mathrm{d}$ axis, and the hypothesis of working with $I_{r d}=0$, confer on the electromagnetic torque the following expression:

$T_{e m}=-p M_{s r} I_{r q} I_{s d}=-p \phi_{r d} I_{r q}$

As we proceed to the magnetization of the machine before applying a speed reference, $\phi_{r d}$ can be replaced by its reference $\phi_{\text {rdref }}$ in the relation (26), therefore:

$T_{e m}=-p \phi_{r d r e f} I_{r q}=K_{e m} I_{r q}$

and

$J \frac{d \Omega}{d t}=K_{e m} I_{r q}-f \Omega-T_{r}$

with $K_{e m}$ being the torque constant. by:

Thus, the transfer function of the speed will be expressed

$$
\Omega(s)=\frac{K_{e m}}{f+J_{S}} I_{r q}(s)-\frac{1}{f+J_{S}} T_{r}(s)
$$

The magnitude $T_{r}(s)$ plays the role of a disturbance input for speed, the principal input being $I_{r q}(s)$. The block diagram of the regulation will be in conformity with that of Figure 3.

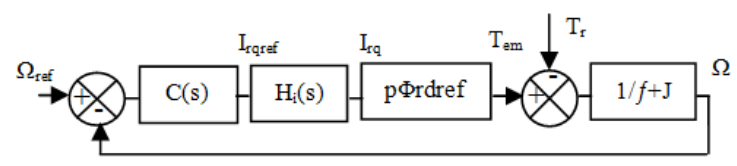

Fig. 3. Speed control chain

\section{VGPI CONTROLLER IN DFIM SPEED CONTROL}

\section{A. VGPI Controller Structure}

The use of PI controllers to command a doubly fed induction motor's speed is often characterized by an overshoot in tracking mode and a poor load disturbance rejection. This is mainly caused by the fact that the gains of the controller cannot be set to solve the overshoot and load disturbance rejection problems simultaneously. Overshoot elimination setting will cause a poor load disturbance rejection, and rapid load disturbance rejection setting will cause important overshoot or even instability in the system.

To overcome this problem, the use of VGPI controllers is proposed. A VGPI controller is a generalization of the classical PI controller where the proportional and integrator gains vary 
along a tuning curve. Each gain of the proposed controller has four tuning parameters [13-15]:

- Gain initial value or start up setting which permits overshoot elimination.

- Gain final value or steady state mode setting which permits rapid load disturbance rejection.

- Gain transient mode function which is a polynomial curve that joints the gain initial value to the gain final value.

- Saturation time which is the time at which the gain reaches its final value.

The degree $n$ of the gain transient mode polynomial function is defined as the degree of the variable gain PI controller.

If $e(t)$ is the signal input to the VGPI controller the output is given by:

$$
y(t)=K_{p} e(t)+\int_{0}^{t} K_{i} e(\tau) d \tau
$$

With:

$$
\begin{gathered}
K_{p}= \begin{cases}\left(K_{p f}-K_{p i}\right)\left(\frac{t}{t_{s}}\right)^{n}+K_{p i} \quad \text { if } \quad t<t_{s} \\
K_{p f} & \text { if } t \geq t_{s}\end{cases} \\
K_{i}= \begin{cases}K_{i f}\left(\frac{t}{t_{s}}\right)^{n} & \text { if } t<t_{s} \\
K_{i f} & \text { if } \quad t \geq t_{s}\end{cases}
\end{gathered}
$$

Where $K_{p i}$ and $K_{p f}$ are the initial and final values of the proportional gain $K_{p}$ and $K_{i f}$ is the final value of the integrator gain $K_{i}$.

The initial value of $K_{i}$ is taken to be zero. It is noted that a classic PI controller is a VGPI controller of degree zero.

The VGPI unit step response is given by:

$$
y(t)= \begin{cases}K_{p i}+\left(K_{p f}-K_{p i}+\frac{K_{i f}}{n+1} t\right)\left(\frac{t}{t_{s}}\right)^{n} & \text { if } \quad t<t_{s} \\ K_{p f}+K_{i f}\left(t-\frac{n}{n+1} t_{s}\right) & \text { if } \quad t \geq t_{s}\end{cases}
$$

If $t\left\langle t_{s}\right.$ the classical PI unit step response is a linear curve beginning at $K_{p f}$ and finishing at $K_{p f}+t_{s} K_{p i}$ whereas the VGPI unit step response $(n \neq 0)$ varies along a polynomial curve of degree $n+1$ beginning at $K_{p i}$ and finishing at $K_{p f}+t_{s} K_{i f} /(n+1)$.
If $t \geq t_{s}$, the unit step responses of a PI and VGPI controllers are both linear with slope $K_{i f}$.

From these results, one can say that a VGPI controller has the same properties with a classical PI controller in the permanent region with damped step response in the transient region.

A VGPI controller could then be used to replace a PI controller when we need to solve the load disturbance rejection and overshoot problems simultaneously.

The VGPI controller in vector control of DFIM is used as presented in Figure 4.

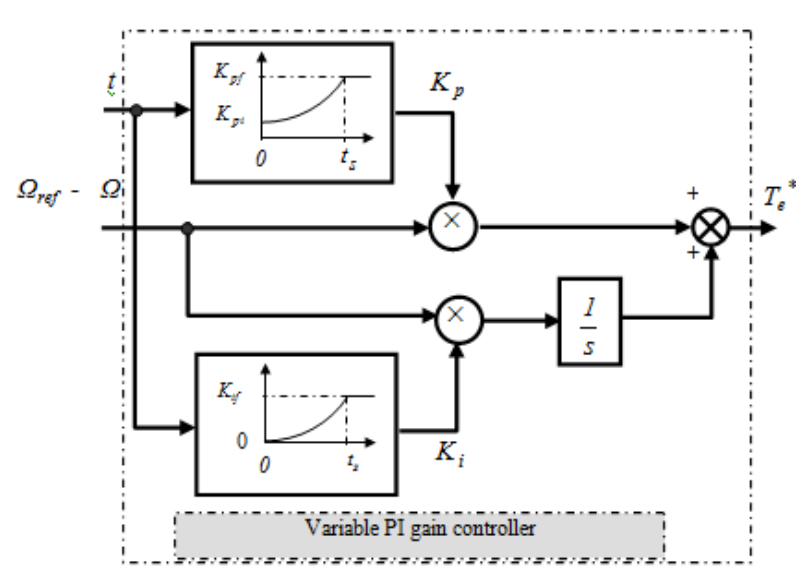

Fig. 4. The Structure of VGPI controller in DFIM vector control

The tuned VGPI controller is given by:

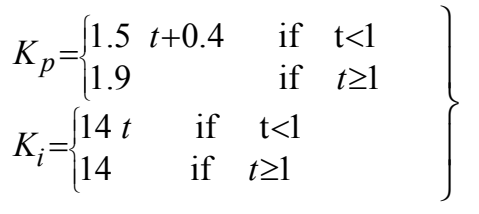

$$
\begin{aligned}
& \text { V. Simulation Results }
\end{aligned}
$$

The DFIM used in this work is a $1.5 \mathrm{~kW}-50 \mathrm{~Hz}$ motor, whose parameters are given in the appendix. The global schema of the state-space nonlinear control of a DFIM using VGPI controllers is presented in Figure 5.

\section{A. Speed Reversal of Rated Value}

In order to make a comparison between the behavior of the conventional PI controller and that of the VGPI controller, studied under different operating conditions, a direct start of the motor under no load is realized with a set point of $157 \mathrm{rad} / \mathrm{s}$ followed by an inversion of the rotation direction at time $t=3 \mathrm{~s}$, external perturbations are introduced by a sudden application of a 10 N.m nominal charge at $\mathrm{t}=1 \mathrm{~s}$ and removed at $\mathrm{t}=2 \mathrm{~s}$. 


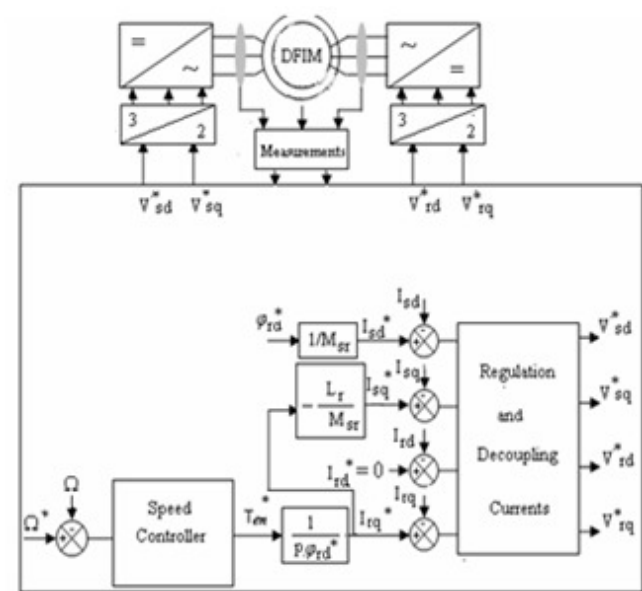

Fig. 5. Block diagram of DFIM speed control using a state space nonlinear approach.

The results given by Figures 6-7 show excellent performance in regulation for the VGPI controller with very good monitoring of the reference speed.

This will result in a much lower tracking error than that obtained using the conventional PI structure. Note also that the orientation of the rotor flux is fully realized; furthermore, the developed electromagnetic torque reproduces its reference satisfactorily.

It can also be noted that the low sensitivity and disturbance rejection are excellent for the VGPI controller which also provides better performance in terms of speed and time disturbance rejection.

\section{B. Robust Control for Different Values of Rotor Resistance}

In order to verify the robustness of VGPI regulator under motor parameters variations, we have simulated the system with rotor resistance variation (increase at $50 \%$ of nominal value rotor resistance). Figures 8-9 show the responses speed and rotor flux in the test of robustness for different values of rotor resistance. The results indicate that the VGPI regulator is insensitive to the resistance change, which results in zero influence on the torque and rotor flux. An increase of the resistance does not have any effect on the performances of the proposed controller. The VGPI controller rejects rapidly the rotor resistance disturbance.

By comparing these results, one can say that varying the gains of a classical PI controller transforms it to a high performance robust controller. A linear variation of the gains (first degree VGPI controller) gave important amelioration. One can mention the setting time value which was almost divided by four or the speed overshoot which was totally eliminated. Better performances could be obtained using higher degree VGPI controllers.
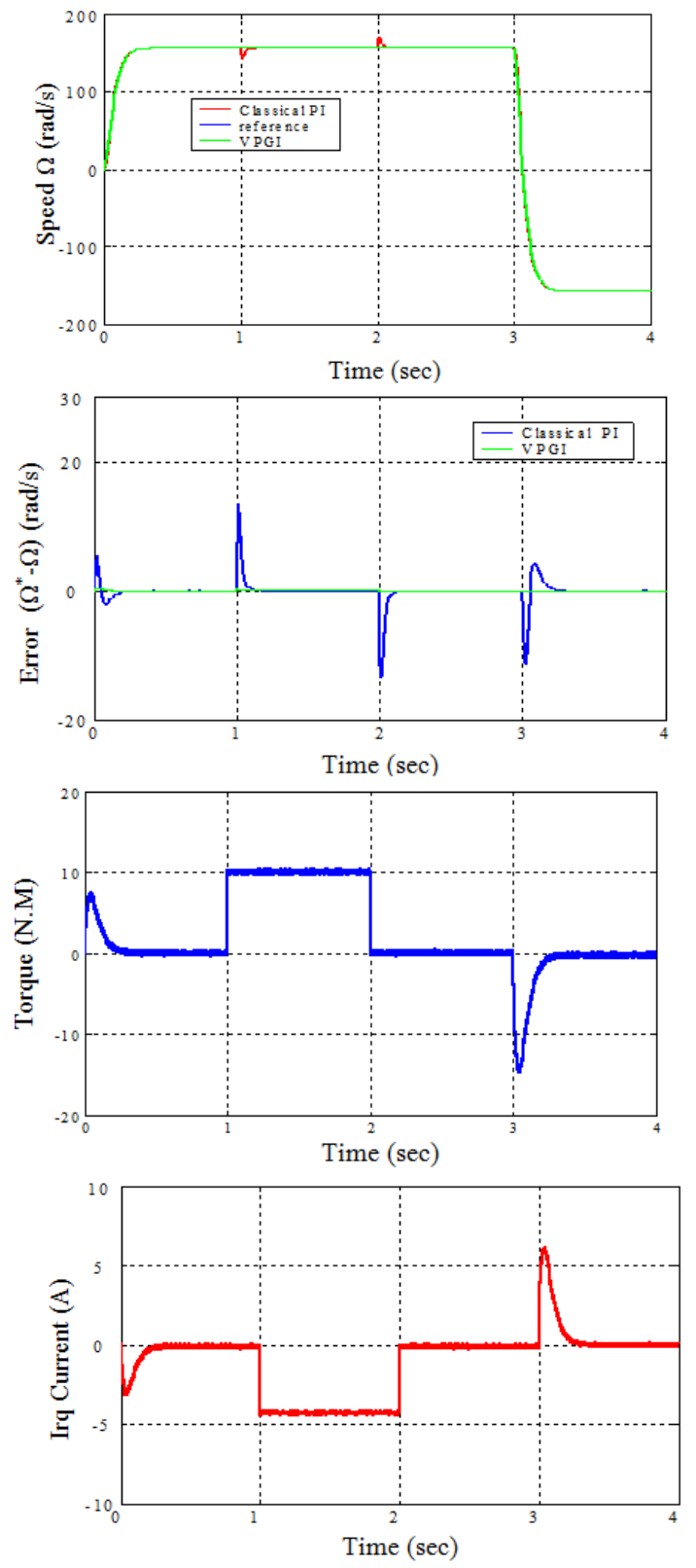

Fig. 6. Simulted results of speed control of DFIM using VGPI

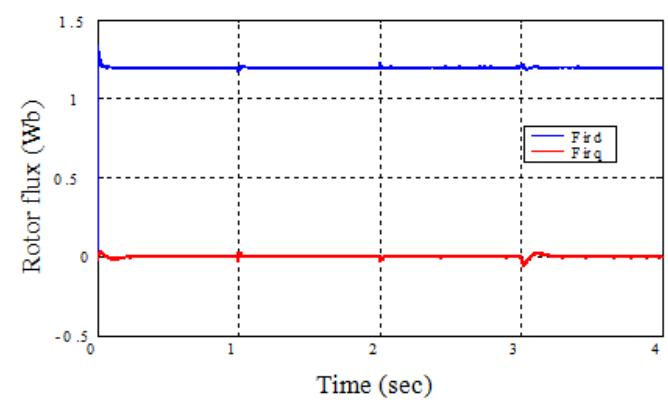

Fig. 7. Response of the two components of the rotor flux 


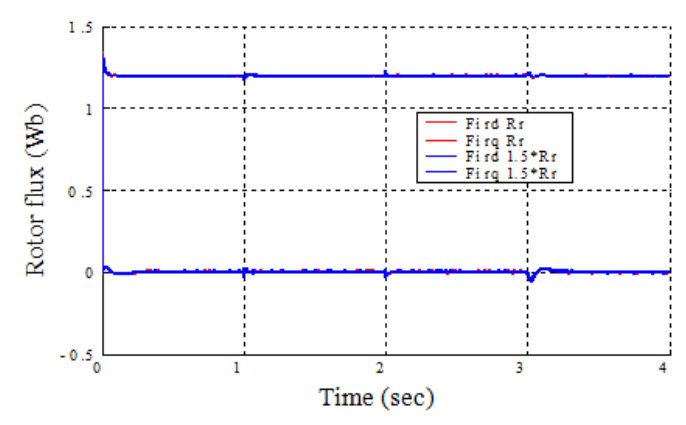

Fig. 8. Test of robustness results for rotor flux for different Values of rotor resistance: nominal case and $+50 \%$.
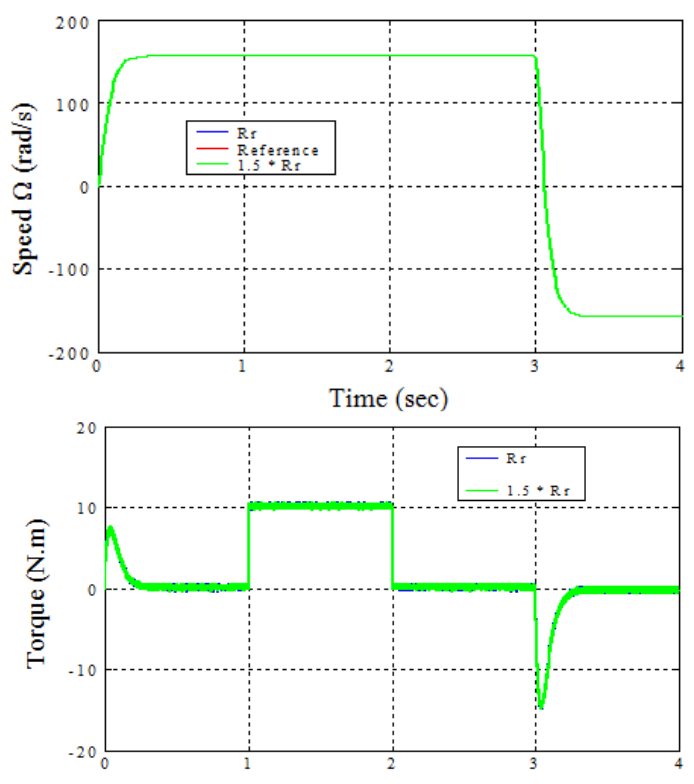

Time (sec)

Fig. 9. Test of robustness results using VGPI for different Values of rotor resistance: nominal case and $+50 \%$.

\section{CONCLUSION}

In this paper, we presented the principle of speed control of a double-fed induction motor using a variable gain PI speed controller. Taking advantage of the accessibility of the current measurement of the motor, a new approach was discussed to allow the decoupling of its currents in a rotating (dq) frame. This principle is based on an input-output decoupling by state space feedback that will serve to obtain very simple currents transfer functions, and therefore, a simplified calculation of the correction. Subsequently, we demonstrated the improvement made by the variable gain PI speed controller on the performance of the DFIM compared to the conventional PI controller. Simulation results demonstrate that VGPI controller outperforms the classical PI controller. Further, that the given first degree VGPI controller eliminates overshoot. The simulation results showed a remarkable behaviour of the VGPI controller during regulation and tracking, with a significantly better disturbance rejection than the classic PI controller. Simulation results have shown correct rotor flux oriented control behaviour and superior speed tracking performances. The VGPI regulator provides robustness against rotor resistance variation and insensitivity to load torque disturbance as well as faster dynamics with negligible steady state error at dynamic operating conditions.

\section{REFERENCES}

[1] G. Salloum, R Mbayed, M Pietrzak-David, B de Fornel, "Mixed sensitivity $\mathrm{H} \infty$ control of doubly fed induction motor", ISIE 2007, IEEE International Symposium on Industrial Electronics, pp. 1300-1304, Vigo, Spain, June 4-7, 2007

[2] A. L. Nemmour, R. Abdessemed, A. Khezzar, L. Louze, M. Boucherma, "The input-output linearization control scheme for a doubly-fed induction motor drive", ICEM 2008, 18th International Conference on Electrical Machines, Vilamoura, Portugal, September 69, 2008

[3] L. Yuan, H. Feng-you, Y. Zong-bin, "Study on sliding mode speed control with fuzzy approach for doubly-fed induction motor", IEEE International Conference on Control and Automation, pp. 2171-2175, Christchurch, New Zealand, December 9-11, 2009.

[4] S. Drid, M. Tadjine, M. S. Nait-Said, "Nonlinear feedback control and torque optimization of a doubly fed induction motor", Journal of Electrical Engineering, Vol. 56, No. 3-4, pp. 57-63, 2005

[5] A. Chaiba, R. Abdessemed, M.L Bendaas, A. Dendouga, "Performances of torque tracking control for doubly fed asynchronous motor using PI and fuzzy logic controllers", Journal of Electrical Engineering, No. 2, Vol. 5, Article No. 5.2.4, 2005

[6] G. Salloum, Contribution à la commande robuste de la machine asynchrone à double alimentation (Contribution at the robust control of doubly fed induction motor), PhD Thesis, National Institut Polytechnic of Toulous, France, 2007

[7] B. Allaoua, A. Abderrahmani, B. Gasbaoui, A. Nasri, "The efficiency of particle swarm optimisation applied on fuzzy logic DC motor speed control", Serbian Journal on Electrical and Engineering, Vol. 5, No. 2, pp. 247-262, 2008

[8] S. Drid, M. Tadjine, M.S. Nait-Said, "Robust backstepping vector control for the doubly fed induction motor", IET Control Theory \& Applications, Vol. 1, No. 4, pp. 861-868, 2007

[9] D. Ben Attous, Y. Bekaka, "Speed control of a doubly fed induction motor using fuzzy logic techniques", International Journal on Electrical Engineering and Inforrmatics, Vol. 2, No. 3, pp. 179-191, 2010

[10] S. K. El Khil, I. Slama-Belkhogja, M. Pietrzak-David, B. de Formel, "A Fault tolerant operating system in a doubly fed induction machine under inverter short-circuit faults", IECON 2006, 32nd Annual Conference on IEEE Industrial Electronics, pp. 1125-1130, Paris, France, November 710,2006

[11] M. S. Vicatos, J. A. Tegopoulos, "A doubly-fed induction machine differential drive model for automobiles", IEEE Transactions on Energy Conversion. Vol. 18, No. 2, pp. 225-230, 2003

[12] P-E. Vidal, M. Pietrzak-David, F. Bonnet, "Mixed control strategy of a doubly fed induction machine", Electrical Engineering, Vol. 90, No. 5, pp. 337-346, 2008

[13] A. Miloudi, “ Etude et conception de régulateurs robustes dans différentes stratégies de commandes d'un moteur asynchrone", $\mathrm{PhD}$ Thesis, Universtity of Mohamed Boudiaf of Oran, Algeria, 2006

[14] A. Miloudi, E. A. A. Radadi, A. D. Draou, "A variable gain PI controller used for speed control of a direct torque neuro fuzzy controlled induction machine drive", Turkish Journal of Electrical Engineering \& Computer Science, Vol. 15, No. 1, pp. 37-49, 2007

[15] A. Miloudi, E. A. A. Radadi, A. D. Draou, Y. Miloud, "Simulation and modelling of a variable gain PI controller for speed control of a direct torque neuro fuzzy controlled induction machine drive", PESC 04, IEEE 35th Annual Power Electronics Specialists Conference, Vol. 5, pp. 3493 3498, Aachen, Germany, June 20-26, 2004 